\title{
A Comparative Study on Local and Newly Introduced Rice Varieties in Ebonyi State of Nigeria based on Selected Agronomic Characteristics
}

\author{
Oko A. O. ${ }^{1}$, Ubi B. E. ${ }^{1,2, *}$, Efisue A. A. ${ }^{2}$ \\ ${ }^{1}$ Department of Biotechnology, Ebonyi State University, P.M.B. 053 Abakaliki, Ebonyi State, Nigeria \\ ${ }^{2}$ Biotechnology Research and Development Centre, Ebonyi State University, P.M.B. 053 Abakaliki, Ebonyi State, Nigeria
}

\begin{abstract}
The Choice of rice varieties by farmers and the rate at which farmers in Ebonyi state go for new rice varieties at the expense of indigenous varieties have become a source of worry to scientists. We assessed the agronomic characteristics of 15 selected indigenous and newly introduced hybrid rice varieties in Ebonyi State, Nigeria. The Rice cultivars were grown under the same conditions and screened for morpho-agronomic traits. Significant variation $(\mathrm{P}<0.05)$ was detected among the 20 rice varieties for all the traits evaluated. The results showed that plant height ranged between $144.01 \mathrm{~cm}$ in "Mass (I)" and $76.00 \mathrm{~cm}$ in "Chinyeugo". Cv. "E4197" had the highest value of $38 \pm 0.02 \mathrm{~cm}$ for panicle length and "Chinyereugo" had the highest value of $6.3 \mathrm{~g} \pm 0.03$ for panicle weight. Leaf area showed the highest value of $63.8 \mathrm{~cm}^{2} \pm 0.01$ in "Mass (I)". Flowering time ranged from $138 \pm 0.1$ days in "Mass (I)" to $68 \pm 0.04$ days in "Chinyereugo" while "Mass (II)" and "E4077" took the shortest period of 14 days after flowering to mature. Cv. "Co-operative" had high number of seeds per panicle (139 \pm 0.19$)$. "Chinyereugo" had the highest value of $25.9 \mathrm{~g} \pm 1.4$ for 1000 -grains weight. The grain of "E4314" was the longest $(8.00 \mathrm{~mm} \pm 0.89)$ of the varieties studied. The grains of "Awilo" had a grain width of $2.62 \mathrm{~mm} \pm 0.04$, while "E4197" had the highest value for grain width of $4.1 \mathrm{~mm}$. Farmers should, therefore, be critical in accepting new varieties that may not be comparably outstanding in a holistic sense, in order to preserve the integrity of the all-cherished indigenous rice varieties .
\end{abstract}

Keywords Rice Genetic Resources, Agronomic Traits, Ebonyi State

\section{Introduction}

Rice is a food crop of world-wide importance and forms the foundation of the diet of over 3 billion people, constituting over half of the world's population[1]. It is widely cultivated throughout the world and has become the second most important cereal in the world after wheat in terms of cultivation, due to a recent decline in maize production[2].

Rice is grown in more than 100 countries under widely differing climatic conditions and is particularly productive in tropical regions with abundant moisture. Rice farmers choose varieties adapted to the region's length of growing season, soil, altitude; and for paddy farmers, the depth of water in the fields. Paddy rice farmers in developing countries usually sow seeds in small seedbeds, then hand- transplant the seedlings into flooded fields that have been levelled by water buffalo or oxen-drawn plows. The centre of origin of rice is believed to be South-East Asia (Oryza sativa) and

* Corresponding author:

ubi.benjamin@yahoo.com (Ubi B. E.)

Published online at http://journal.sapub.org/ijaf

Copyright (C) 2012 Scientific \& Academic Publishing. All Rights Reserved
Africa (O. glaberrima) with some of the rice producing countries being China, Burma, India,Indonesia, Japan, United States, Spain, Italy and Brazil, before its spread to Africa[3]. Although the original parental species of rice are native to South-East Asia and certain parts of Africa, centuries of trade and exportation have made it common place in many cultures world-wide[4].

Much of the foreign rice imported into West Africa is from South East Asia, where rice has been an ancient crop under cultivation and first mentioned in history as far back as 2800 $\mathrm{BC}$ in China. Rice has the potential to improve nutrition, boost food security, foster rural development and support sustainable land use in Africa[5]. In sub-Saharan Africa, West Africa is the leading producer and consumer of rice and accounts for about 64.2 and $61.9 \%$ of total rice production and consumption, respectively. Except for Burkina Faso and Niger, rice is a staple crop throughout West Africa, especially in Cote d'lvoire, the Gambia, Guinea, Guinea Bissau, Liberia, Senegal and Sierra Leone. The River Niger drainage system is a major rice growing environment in the region. Nigeria has a leading role in rice production in West Africa, ranking highest as both the producer and consumer of rice in the sub-region with production figures slightly above 
$50 \%[6]$.

In Nigeria, rice is important for several reasons including being a major contributor to internal and sub-regional trade. Two types of rice have been mainly cultivated in Nigeria: the African rice (Oryza glaberrima) and the Asian rice (Oryza sativa). In recent times, however, new rice varieties have also been introduced including the West African Rice Development Association's (WARDA) hybrid rice varieties referred to as NERICA i.e. New Rice for Africa, which are interspecific hybrids between the African and Asian rice. According to Jones[2], the African rice O. glaberrima originated from the wild rice $(O$. barthii) some 3500 years ago and its offspring domesticated probably in the inland delta area of Nigeria from where it spread through the upper Niger valley to the rest of West Africa. African rice is cultivated as field crop and a paddy crop. For the Niger Benue trough, Sokoto - Rima and Chad Basin, rice has been in cultivation long enough for a rice culture to evolve going as far back as $1500 \mathrm{BC}[6]$.

Rice is rich in genetic diversity, with thousands of varieties grown throughout the world and its economic importance related to agro-ecological adaptation, household food security, ceremonies, nutritional diversification, income generation and employment[7]. Remarkable deepwater varieties of $O$. glaberrima exist which are specific to the unusual flood conditions that occur in the inland Niger Delta, the Sokoto-Rima valley and other flood plains of the extreme north of Nigeria. O. glaberrima is known by different local names as "hakorin montol" in Plateau / Nasarawa area and jatau (red) throughout Hausa land and the Chad Basin. The ecological adaptation of the two species may be more important from the point of view of human selection. The $O$. glaberrima varieties have certain negative features with respect to $O$. sativa: e.g. the seed shatters easily, the grain is brittle and difficult to mill and, most importantly, the yields are lower. But the O. glaberrima types also offer distinct advantages: tolerates fluctuations in water depth, iron toxicity, infertile soils, and adaptation to the ecological conditions of Africa[5]. However, the Asian rice has long been introduced into Nigeria and is gradually displacing the African rice due to its superior attributes. Consequently, local rice farmers in Nigeria have long adopted the Asian rice and some local names given to such rice varieties based on their quality attribute and/or the person that introduced such varieties. As such, two or more local rice varieties in various localities may actually be the same (single) cultivar. An estimated 25 percent of Nigeria's rice is under rain-fed low land cultivation. This ecology is said to contribute between 43 and 45 percent of national rice production[6,8]. The lowland ecology comprises of the shallow Fadama and deep Fadama. A distinguishing feature of this system is that the soil must be covered completely by water at some stage in the growth cycle[9]. Excessive flooding, iron toxicity and lack of water control structure have been the bane of lowland swamp rice production in Ebonyi State particularly in the Abakaliki area. Farmers in Ebonyi State have interesting farming system whereby giant mounds are made at the onset of rains and yams planted at the top of the mound and groundnut at the base. With the early rains, groundnut is harvested and the mound broken down and puddled by hand and crop residue incorporated into the soil. At this time, the fields are flooded and rice is transplanted. Although this system suffices, there can be total crop failure in a year when the cross river overflows its banks[6]. Total crop failure in this case means low production, which seriously affects the chemical composition and agronomic characters of rice. Total crop failure also leads to reduction in the grain quality and the organoleptic properties of the lowland rice.

The production of rice represents $38.89 \%$ of total cereal production in Nigeria. Presently, global rice production stands at 596.5 million tons from 155 million hectares (ha) in 1999. Rice produced in Ebonyi is marketed to states around the region, and the rice production and commercialization chain is well developed[10]. The objective of this work therefore was to assess the variation in the agronomic traits of the selected indigenous and newly introduced rice varieties in order to provide a comparative measure of their growth and yield potential.

\section{Materials and Methods}

\subsection{Collection of Plant Materials}

A total of fifteen rice cultivars were collected from Ebonyi rice farmers at their farm sites during harvest. Five rice cultivars each were collected from Ebonyi North senatorial zone (Abakaliki Area), Ebonyi Central senatorial zone (Ikwo Area) and Ebonyi South Senatorial zone (Afikpo Area). In addition, five new hybrid rice varieties were collected from the Alliance for a Green Revolution in Africa (AGRA) research project at the Biotechnology Research and Development Centre of Ebonyi State University, Abakaliki. The different rice cultivars (which were all $O$. sativa types), the actual identities of the locally named cultivars, their sources and dates of collection are as shown in Table 1 . The rice cultivars were all planted on the field under similar cultural practices.

\subsection{Field Experimental Layout and Establishment}

The plant materials were cultivated at the rice crossing block of the Biotechnology Research and Development Centre located at the Presco Campus of Ebonyi State University, Abakaliki. The land was cleared and the grasses burnt in order to kill any rice contaminants that may be present in the piece of land under cultivation. After burning, the land was ploughed and harrowed manually. The experimental layout was a randomized complete block design (RCBD) and the cultivars were randomly allocated to each experimental plot measuring $1.0 \times 1.0 \mathrm{~m}$. Three seeds were initially sown per hole at a plant spacing of $20 \times 20 \mathrm{~cm}$ with an inter-plot spacing of $40 \mathrm{~cm}$ created to aid easy movement between the plots. At 15 days after seedling emergence, the seedlings were thinned to 2 seedlings per hole giving a total of 50 plants per plot. Each plot containing a cultivar was 
replicated three times. The rice experimental plot was irrigated with the help of an overhead sprinkler irrigation facility belonging to the Alliance for a Green Revolution in Africa (AGRA) that was located in the rice field. The irrigation was done immediately after sowing the seeds as the rice seeds needed sufficient water to germinate and this was continued all through the period of cultivation. Weeding was carried out manually at 21 days after sowing and a second weeding during panicle initiation (42 days after sowing). The whole rice field was covered with a net during fruiting to prevent birds from destroying the young fruits. A basal dose of N-P-K fertilizer (15:15:15) at the rate of $200 \mathrm{~kg} / \mathrm{ha}$ was applied at 15 days after sowing (as soon as the weeds have been removed). Subsequently, urea was top-dressed at the rate of $100 \mathrm{~kg} / \mathrm{ha}$ at 30 days after sowing.

\subsection{Data Collection for Agronomic Characters}

Flowering time was measured as the number of days from sowing to $50 \%$ flowering and was recorded separately for each plot. Leaf area (LA) was measured by tracing the outline of the leaves onto a standard mass/area paper. The leaf trace on the paper was carefully cut out with scissors and its weight measured with a digital weighing balance. The weight of the paper was used to calculate the corresponding area of the leaf with high precision. For the determinate cultivars, the third fully developed leaves counting from the apex of the plants were sampled for leaf area measurement whereas the middle leaves were used for the indeterminate plants. However, both the third fully expanded and middle leaves corresponded in most of the plants. LA was measured in replicates of three. Plant height was measured by running a thread from the base of the plant to the apex and measuring the length of the thread with a meter rule to the nearest centimetre. Panicle length was similarly measured. The number of seeds per panicle and panicle number were directly counted, while panicle weight was estimated using electronic weighing balance. At maturity, the rice within each plot were harvested, threshed carefully, winnowed and pertinent data on yield components recorded. All measurements were taken in triplicates. The rice grains were sun-dried to about $14 \%$ moisture content and preserved for the analysis.

\subsection{Data Analysis}

All data were analysed by the Analysis of Variance (ANOVA) procedure using SAS software version 9.1 (SAS Institute, 1998). Differences were declared statistically significant when $P \leq 0.05$. Where significant differences were detected, the means were separated by the least significant difference (LSD) at $5 \%$ probability level. Interrelationships among traits values were estimated using the Pearson correlation coefficient.

Table1. Rice Genetic Resources used in this Study

\begin{tabular}{|c|c|c|c|c|}
\hline S/No. & Local name / Cultivar & Cultivar identity of local name & Species & Location collected \\
\hline 1 & Sipi & FARO 44 & O. sativa & Ebonyi North Senatorial Zone \\
\hline 2 & Faro 14 (I) & - & O. sativa & Ebonyi North Senatorial Zone \\
\hline 3 & Awilo & $\mathrm{xxx}$ & O. sativa & Ebonyi North Senatorial Zone \\
\hline 4 & Canada & ITA 315 & O. sativa & Ebonyi North Senatorial Zone \\
\hline 5 & Faro $15(\mathrm{I})$ & - & O. sativa & Ebonyi North Senatorial Zone \\
\hline 6 & Mass III & A collection of all long-grained rice & O. sativa & Ebonyi Central Senatorial Zone \\
\hline 7 & Faro 14 (II) & - & O. sativa & Ebonyi Central Senatorial Zone \\
\hline 8 & Faro 15 (II) & - & O. sativa & Ebonyi Central Senatorial Zone \\
\hline 9 & Chinyereugo & $\mathrm{xxx}$ & O. sativa & Ebonyi Central Senatorial Zone \\
\hline 10 & China & ITA306 & O. sativa & Ebonyi Central Senatorial Zone \\
\hline 11 & Onuogwu & $\mathrm{xxx}$ & O. sativa & Ebonyi South Senatorial Zone \\
\hline 12 & Co-operative & $\mathrm{xxx}$ & O. sativa & Ebonyi South Senatorial Zone \\
\hline 13 & Mass I & A collection of all long-grained rice & O. sativa & Ebonyi South Senatorial Zone \\
\hline 14 & Mass II & A collection of all long-grained rice & O. sativa & Ebonyi South Senatorial Zone \\
\hline 15 & Ezichi & $\mathrm{xxx}$ & O. sativa & Ebonyi South Senatorial Zone \\
\hline 16 & IR77384 - 12-17-3(E4077) & - & O. sativa & AGRA \\
\hline 17 & IR68 (E4197) & - & O. sativa & AGRA \\
\hline 18 & P5BRc50 (E4212) & - & O. sativa & AGRA \\
\hline 19 & IR77647-3B -8-2-2-14-4 (E4314) & - & O. sativa & AGRA \\
\hline 20 & IR75395-2B-B-1 -1-1-2-4 (E4334) & - & O. sativa & AGRA \\
\hline
\end{tabular}

$\mathrm{xxx}=$ indicates cultivars which could not be identified

- = indicates cultivars whose local name is the real identity 
Table 2. Mean Values of some of the Measured Agronomic Traits of the Rice Cultivars used in this Study*

\begin{tabular}{|c|c|c|c|c|c|c|c|c|}
\hline S/No & Rice cultivar & $\begin{array}{l}\text { Plant Height } \\
(\mathrm{cm})\end{array}$ & $\begin{array}{l}\text { Leaf area } \\
\left(\mathrm{cm}^{2}\right)\end{array}$ & $\begin{array}{l}\text { No. of } \\
\text { panicles } \\
\text { per plant }\end{array}$ & $\begin{array}{l}\text { Panicle } \\
\text { weight }(\mathrm{g})\end{array}$ & $\begin{array}{l}\text { Panicle } \\
\text { length }(\mathrm{cm})\end{array}$ & $\begin{array}{l}\text { No. of seed / } \\
\text { panicle }\end{array}$ & $\begin{array}{l}\text { Days to } 50 \% \\
\text { flowering }\end{array}$ \\
\hline 1 & Sipi & $82.6^{Q}$ & $40.80^{\mathrm{F}}$ & $8.5^{\mathrm{H}}$ & $3.20^{\mathrm{J}}$ & $21.90^{\mathrm{L}}$ & $101^{\mathrm{H}}$ & $86^{\mathrm{J}}$ \\
\hline 2 & Faro 14 (I) & $96.3^{\mathrm{J}}$ & $32.70^{\mathrm{H}}$ & $9.3^{\mathrm{L}}$ & $4.20^{\mathrm{E}}$ & $22.40^{\mathrm{J}}$ & $72^{\mathrm{L}}$ & $131^{\mathrm{B}}$ \\
\hline 3 & Faro 15 (I) & $85.4^{\mathrm{M}}$ & $44.60^{\mathrm{E}}$ & $14.6^{\mathrm{H}}$ & $3.90^{\mathrm{GF}}$ & $21.50^{\mathrm{M}}$ & $101^{\mathrm{H}}$ & $129^{\mathrm{CD}}$ \\
\hline 4 & Awilo & $84.7^{\mathrm{N}}$ & $44.40^{\mathrm{E}}$ & $9.3^{\mathrm{J}}$ & $4.70^{\mathrm{C}}$ & $24.70^{\mathrm{F}}$ & $127^{\mathrm{D}}$ & $126^{\mathrm{D}}$ \\
\hline 5 & Canada & $113.0^{\mathrm{G}}$ & $46.04^{I}$ & $9.0^{\mathrm{D}}$ & $2.80^{\mathrm{M}}$ & $19.50^{\mathrm{P}}$ & $85 \mathrm{~J}$ & $80^{\mathrm{L}}$ \\
\hline 6 & MASS III & $66.7^{\mathrm{T}}$ & $31.00^{\mathrm{G}}$ & $8.0^{\mathrm{I}}$ & $3.40^{\mathrm{I}}$ & $19.80^{\circ}$ & $102^{\mathrm{H}}$ & $76^{\mathrm{M}}$ \\
\hline 7 & FARO 14 (II) & $84.00^{\circ}$ & $34.10^{\mathrm{M}}$ & $7.7^{\mathrm{H}}$ & $4.50^{\mathrm{D}}$ & $23.50^{\mathrm{G}}$ & $95^{\mathrm{I}}$ & $70^{\mathrm{N}}$ \\
\hline 8 & FARO 15 (II) & $99.6^{\mathrm{I}}$ & $27.10^{\mathrm{M}}$ & $8.7^{\mathrm{B}}$ & $3.80^{\mathrm{G}}$ & $22.80^{\mathrm{I}}$ & $102^{\mathrm{H}}$ & $72^{N}$ \\
\hline 9 & CHINYEREUGO & $76.00^{\mathrm{s}}$ & $28.10^{\mathrm{L}}$ & $12.7^{\mathrm{H}}$ & $6.30^{\mathrm{A}}$ & $22.40^{\mathrm{J}}$ & $137^{\mathrm{B}}$ & $68^{\circ}$ \\
\hline 10 & CHINA & $94.3^{\mathrm{K}}$ & $31.30^{\mathrm{I}}$ & $7.3^{\mathrm{D}}$ & $3.10^{\mathrm{KJ}}$ & $22.20^{\mathrm{K}}$ & $79^{\mathrm{L}}$ & $81^{\mathrm{L}}$ \\
\hline 11 & Onuogwu & $141^{\mathrm{B}}$ & $47.80^{\mathrm{C}}$ & $12.0^{\mathrm{L}}$ & $4.0^{\mathrm{F}}$ & $24.90^{\mathrm{E}}$ & $127^{\mathrm{D}}$ & $130^{\mathrm{CB}}$ \\
\hline 12 & Co-operative & $83.4^{\mathrm{P}}$ & $33.70^{\mathrm{G}}$ & $12.3^{\mathrm{A}}$ & $3.6^{\mathrm{H}}$ & $26.40^{\mathrm{C}}$ & $139^{\mathrm{A}}$ & $100^{\mathrm{HI}}$ \\
\hline 13 & Mass (I) & $144.01^{\mathrm{A}}$ & $63.80^{\mathrm{A}}$ & $10.3^{\mathrm{I}}$ & $4.5^{\mathrm{D}}$ & $24.70^{\mathrm{F}}$ & $96^{1}$ & $138^{\mathrm{A}}$ \\
\hline 14 & Mass (II) & $91.4^{\mathrm{L}}$ & $63.10^{\mathrm{B}}$ & $9.3^{\mathrm{F}}$ & $4.4^{\mathrm{D}}$ & $25.10^{\mathrm{E}}$ & $121^{\mathrm{F}}$ & $84^{\mathrm{K}}$ \\
\hline 15 & Ezichi & $116.01^{\mathrm{F}}$ & $29.11^{\mathrm{J}}$ & $9.3^{\mathrm{E}}$ & $3.9^{\mathrm{GF}}$ & $25.70^{\mathrm{D}}$ & $106^{\mathrm{G}}$ & $103^{\mathrm{G}}$ \\
\hline 16 & E4077 & $80.4^{\mathrm{R}}$ & $17.74^{\mathrm{P}}$ & $11^{\mathrm{F}}$ & $2.90^{\mathrm{ML}}$ & $23.60^{\mathrm{G}}$ & $124^{\mathrm{E}}$ & $108^{\mathrm{E}}$ \\
\hline 17 & E4197 & $134.2^{\mathrm{C}}$ & $28.60^{\mathrm{K}}$ & $12^{\mathrm{F}}$ & $4.90^{\mathrm{B}}$ & $29.00^{\mathrm{B}}$ & $126^{\mathrm{D}}$ & $105^{\mathrm{F}}$ \\
\hline 18 & $\mathrm{E} 4212$ & $119.3^{\mathrm{E}}$ & $17.35^{\mathrm{P}}$ & $10^{\mathrm{GF}}$ & $2.90^{\mathrm{ML}}$ & $20.10^{\mathrm{N}}$ & $106^{\mathrm{G}}$ & $101^{\mathrm{HG}}$ \\
\hline 19 & $\mathrm{E} 4314$ & $122.01^{\mathrm{D}}$ & $19.29^{\circ}$ & $9.7^{\mathrm{M}}$ & $3.00^{\mathrm{KL}}$ & $23.20^{\mathrm{H}}$ & $85^{J}$ & $76^{\mathrm{M}}$ \\
\hline \multirow[t]{4}{*}{20} & $\mathrm{E} 4334$ & $106.8^{\mathrm{H}}$ & $25.28^{\mathrm{N}}$ & $11.7^{\mathrm{I}}$ & $3.50^{\mathrm{H}}$ & $30.10^{\mathrm{A}}$ & $132^{\mathrm{C}}$ & $99^{\mathrm{I}}$ \\
\hline & Mean $\pm \mathrm{SE}$ & $101.1 \pm 22.4$ & $35.28 \pm 12.94$ & $10.14 \pm 1.91$ & $3.88 \pm 0.85$ & $23.68 \pm 2.74$ & $108.13 \pm 19.58$ & $98.28 \pm 22.51$ \\
\hline & Prob. & 0.0001 & 0.0001 & 0.0001 & 0.0001 & 0.0001 & 0.0001 & 0.0001 \\
\hline & $\mathrm{LSD}_{005}$ & 0.36 & 0.39 & 1.41 & 0.16 & 0.15 & 1.74 & 1.8 \\
\hline
\end{tabular}

*Means with the same letters are not significantly different from each other at $\mathrm{P} \leq 0.05$.

\section{Results}

The mean values of the traits evaluated in this study, viz: plant height, leaf area, number of panicles per plant, panicle weight, panicle length, number of seeds/panicle and days to $50 \%$ flowering are shown in Table 2 . The cultivars showed significant differences for these traits $(\mathrm{P}<0.0001)$ which suggest the existence of wide variation in the cultivars used in this study. The $\operatorname{LSD}_{0.5}$ values indicate the occurrence of real differences among the accessions tested. The mean plant height among the cultivars was $101 \pm 22.4 \mathrm{~cm}$, which ranged from $66.7-144 \mathrm{~cm}$. "Mass III" had the least plant height $(66.7 \mathrm{~cm})$ followed by "Chinyereugo" $(76.00 \mathrm{~cm})$, while "Mass II" was the tallest cultivar (Table 2). Leaf area significantly varied from $17.74-63.83 \mathrm{~cm}^{2}$ with a mean value of $35.28 \pm 12.94 \mathrm{~cm}^{2}$. The newly introduced AGRA rice cultivars such as "E4212", "E4077", "E4314" have relatively small leaf area compared with other cultivars with relatively higher values for leaf area e.g. "MASS I", "MASS II", "Onugwuo", etc. (Table 2). Mean panicle number per plant was highest (14.6) in "Faro 15(I)", while "China" had the least number of panicles/plant of 7.3. The mean value among the 20 accessions is $10.14 \pm 1.91$ panicles per plant (Table 2). Panicle weight among the 20 accessions ranged from 2.9 to $6.3 \mathrm{~g}$ with a mean weight of $3.88 \pm 0.85 \mathrm{~g}$. Two of the newly improved AGRA rice varieties, "E4077" and "E4212" had the least panicle weight of $2.90 \mathrm{~g}$, while "Chinyereugu" had the highest value for panicle weight $(6.30 \mathrm{~g})$. The length of the panicles also varied significantly among the cultivars and ranged from $19.50 \mathrm{~cm}$ in "Canada" to $30.10 \mathrm{~cm}$ in "E4334" with a mean length of $23.68 \pm 2.74$ $\mathrm{cm}$. Significant variation was obtained in number of seeds per panicle among the studied rice accessions with a mean value of $108.13 \pm 19.58$ seeds/panicle which ranged from 72 seeds/panicle in "Faro14 (I)", 79 seeds/panicle in "China" to the highest value of 139 seeds/panicle in "Co-operative" (Table 2). The number of days to $50 \%$ flowering significantly varied among the 20 accessions studied and ranged from $70-138$ days with a mean value of $98.28 \pm 22.51$ days among the 20 cultivars. "Chinyereugo" had the shortest flowering time of 68 days, followed by "MASS III" and "E4314" which attained $50 \%$ flowering in 72 days, while much delay in flowering was observed in "MASS I" (i.e. 138 days) as shown in Table 2.

Table 3. Correlation Coefficients for Plant Height (PH), Leaf Area (LA), Number of Panicles/Plant (NP/P), Panicle Weight per Plant (PW/P), Panicle Length per Plant (PL/P), and Days to $50 \%$ Flowering (DTF) observed among the 20 rice cultivars*

\begin{tabular}{ccccccc}
\hline & PH & LA & NP/P & PW/P & PL/P & DTF \\
\hline PH & 1.000 & 0.169 & -0.099 & -0.048 & 0.328 & 0.390 \\
& & $(0.196)$ & $(0.453)$ & $(0.715)$ & $(0.011)$ & $(0.002)$ \\
LA & 1.000 & -0.022 & 0.271 & 0.023 & 0.351 \\
& & & $(0.869)$ & $(0.036)$ & $(0.863)$ & $(0.006)$ \\
NP/P & & & 1.000 & 0.397 & 0.573 & 0.082 \\
& & & $(0.002)$ & $(<0.0001)$ & $(0.534)$ \\
PW/P & & & 1.000 & 0.303 & 0.088 \\
& & & & $(0.019)$ & $(0.505)$ \\
PL/P & & & & 1.000 & 0.257 \\
& & & & & & $(0.047)$ \\
DTF & & & & & & 1.000 \\
\hline
\end{tabular}

*Values in parenthesis indicate probability level

Table 3 shows the correlation coefficients observed among the agronomic traits evaluated in this study. Significant correlations were observed between plant height and panicle length $(r=0.328, p=0.011)$, plant height and days to 
flowering $(r=0.390, p=0.002)$; leaf area and panicle weight $(\mathrm{r}=0.271, \mathrm{p}=0.036)$, and leaf area and days to flowering $(\mathrm{r}$ $=0.351, p=0.006)$; number of panicles per plant and panicle weight $(r=0.397, p=0.002)$, and number of panicles per plant and panicle length $(\mathrm{r}=0.573, \mathrm{p}<0.0001)$; panicle length and panicle weight $(r=0.303, p=0.019)$, and panicle length and days to flowering $(r=0.257, p=0.047)$. The significant correlation coefficients among these agronomic traits were generally low and positive in direction, with the exception of the moderate correlation value observed between number of panicles per plant and panicle length (Table $3)$.

The results of variability in grain quality characteristics such as 1000-grain weight, grain length, grain width, length/width ratio, grain shape and grain colour observed among the 20 varieties is as shown in Table 4. Highly significant differences $(p<0.0001)$ were observed in these traits, with real differences between the cultivars indicated by the $\mathrm{LSD}_{0.05}$ values. The 1000 -grain weight ranged from $17.20-$ $25.90 \mathrm{~g}$ with a mean value of $21.46 \pm 2.74 \mathrm{~g}$. Cultivars "E4334" (17.20 g), "MASS II" (17.93 g), "Co-operative" (18.87 g), "FARO 14 (I)" (18.87 g), etc. were among the cultivars that are quite low in seed weight, while "Chinyereugo" (25.90 g), "FARO 15(I)" (25.03 g), "FARO 15 (II)" $(24.00 \mathrm{~g})$ have a high 1000-seed weight (Table 4). Grain "Sipi" had the least grain length (4.46 mm), "FARO 14(I)", length ranged from $4.46-8.00 \mathrm{~mm}$ among the cultivars with a mean grain length value of $6.61 \pm 0.82 \mathrm{~g}$ (Table 4). Cultivar "FARO 15(I \& II)", “Awilo", "MASS III, I \& II", “Onuog- wu", "Chinyereugo", "Co-operative", "Ezichi" and "E4077" had value of grain length close to the mean value, while three of the newly introduced rice varieties "E4197", "E4314" and "E4334" possessed high grain length value. The grain of" E4314" was the longest $(8.00 \mathrm{~mm})$ of all the varieties studied as shown in Table 4.

The width of the grain significantly varied among the cultivars ranging from $1.90 \mathrm{~mm}$ in cv. "E4197" to $2.62 \mathrm{~mm}$ in cv. "Awilo", with a mean value of $2.25 \pm 0.21 \mathrm{~mm}$ among the 20 cultivars (Table 4). Furthermore, the ratio of length to width for all the varieties studied ranged from $1.83-4.10$, with a mean value of $2.97 \pm 0.54$. The cv. "E4197" had the highest value for length/width ratio, followed by "E4314" and "E4334", while "Sipi" recorded the least value followed by "Canada", "Awilo" and "Faro15(I)". In regard to grain shape, most of the farmers' varieties had grains that were medium in shape, while the hybrid varieties had long grains that were slender (SL) to medium (M). The grain shape of "Sipi" was typically short and bold (S\&B) [Table 4]. All the newly introduced hybrid varieties were white in colour while the varieties obtained from the farmers' field were either mixed (M) or white (W) in colour.

Among the grain quality traits, significant correlations were found between 1000-grain weight and grain width $(\mathrm{r}=$ $0.325, \mathrm{p}=0.011), 1000$-grain weight and grain length / width ratio $(r=-0.384, p=0.002)$; grain length and grain length / width ratio $(\mathrm{r}=0.802, \mathrm{p}<0.0001)$; and between grain width and grain length / width ratio $(\mathrm{r}=-0.522, \mathrm{p}<0.001)$.

Table 4. Mean values of Grain Quality Traits of the 20 Rice Cultivars *

\begin{tabular}{|c|c|c|c|c|c|c|c|}
\hline & Cultivar & 1000- GW (g) & $\mathrm{GL}(\mathrm{mm})$ & GWi (mm) & GL/ GWi ratio & $\mathrm{GSh}^{*}$ & Color $^{\S}$ \\
\hline 1 & Sipi & $23.83^{\mathrm{dc}}$ & $4.46^{\mathrm{f}}$ & $2.44^{\text {egf }}$ & $1.83^{1}$ & S\&B & $\mathrm{W}$ \\
\hline 2 & Faro 14 (I) & $18.87^{\text {hg }}$ & $6.78^{\mathrm{d}}$ & $2.10^{\mathrm{ghf}}$ & $3.23^{\mathrm{c}}$ & $\mathrm{L} / \mathrm{SL}$ & W \\
\hline 3 & Faro 15 (I) & $25.03^{\mathrm{bc}}$ & $6.58^{\mathrm{de}}$ & $2.56^{\text {egdf }}$ & $2.57^{\mathrm{ji}}$ & M & W \\
\hline 4 & Awilo & $26.50^{\mathrm{a}}$ & $6.58^{\mathrm{de}}$ & $2.62^{\mathrm{a}}$ & $2.51^{\mathrm{j}}$ & M & M \\
\hline 5 & Canada & $20.80^{\mathrm{fe}}$ & $6.00^{\mathrm{e}}$ & $2.60^{\mathrm{ba}}$ & $2.31^{\mathrm{k}}$ & M & M \\
\hline 6 & Mass III & $20.40^{\mathrm{f}}$ & $6.80^{\mathrm{d}}$ & $2.20^{\mathrm{egdf}}$ & $3.20^{\mathrm{dc}}$ & SL & W \\
\hline 7 & Faro 14 (II) & $20.00^{\mathrm{fg}}$ & $6.10^{\mathrm{e}}$ & $2.30^{\mathrm{dc}}$ & $2.80^{\mathrm{hg}}$ & M & M \\
\hline 8 & Faro 15 (II) & $24.00^{\mathrm{dc}}$ & $6.40^{\mathrm{d}}$ & $2.40^{\mathrm{dc}}$ & $2.70^{\mathrm{hi}}$ & M & M \\
\hline 9 & Chinyereugo & $25.90^{\text {ba }}$ & $6.60^{\mathrm{dc}}$ & $2.50^{\mathrm{ac}}$ & $2.60^{\mathrm{hji}}$ & M & M \\
\hline 10 & China & $19.80^{\mathrm{fg}}$ & $6.00^{\mathrm{e}}$ & $2.20^{\text {egdf }}$ & $2.70^{\mathrm{hgi}}$ & M & M \\
\hline 11 & Onuogwu & $23.20^{\mathrm{d}}$ & $6.46^{\mathrm{de}}$ & $2.46^{\mathrm{ac}}$ & $2.62^{\mathrm{g}}$ & M & M \\
\hline 12 & Co-operative & $18.87^{\text {hg }}$ & $6.56^{\mathrm{de}}$ & $2.10^{\mathrm{dc}}$ & $3.12^{\mathrm{dce}}$ & $\mathrm{M} / \mathrm{SL}$ & W \\
\hline 13 & Mass (I) & $20.17^{\mathrm{f}}$ & $6.84^{\mathrm{de}}$ & $2.24^{\mathrm{df}}$ & $3.05^{\mathrm{fe}}$ & $\mathrm{L} / \mathrm{SL}$ & W \\
\hline 14 & Mass (II) & $17.93^{\text {hi }}$ & $6.50^{\mathrm{dc}}$ & $2.10^{\mathrm{eghf}}$ & $3.10^{\mathrm{de}}$ & $\mathrm{SL} / \mathrm{M}$ & W \\
\hline 15 & Ezichi & $20.30^{\mathrm{fg}}$ & $6.58^{\mathrm{de}}$ & $2.22^{\text {egdf }}$ & $2.96^{\mathrm{f}}$ & M & M \\
\hline 16 & E4077 & $20.40^{\mathrm{f}}$ & $6.70^{\mathrm{d}}$ & $2.20^{\text {egdf }}$ & $3.00^{\mathrm{fe}}$ & $\mathrm{L} / \mathrm{M}$ & W \\
\hline 17 & E4197 & $24.50^{\mathrm{c}}$ & $7.80^{\text {ba }}$ & $1.90^{\mathrm{h}}$ & $4.10^{\mathrm{a}}$ & Extra L/SL & W \\
\hline 18 & E4212 & $21.80^{\mathrm{e}}$ & $6.90^{\mathrm{dc}}$ & $2.20^{\mathrm{egdf}}$ & $3.10^{\mathrm{de}}$ & $\mathrm{L} / \mathrm{SL}$ & W \\
\hline 19 & E4314 & $20.20^{\mathrm{f}}$ & $8.00^{\mathrm{a}}$ & $2.00^{\mathrm{gh}}$ & $4.00^{\mathrm{a}}$ & Extra L/SL & W \\
\hline 20 & E4334 & $17.20^{\mathrm{i}}$ & $7.40^{\mathrm{bc}}$ & $2.20^{\text {egdf }}$ & $3.80^{\mathrm{b}}$ & $\mathrm{L} / \mathrm{SL}$ & W \\
\hline & Mean SE & $21.46 \pm 2.74$ & $6.61 \pm 0.82$ & $2.25 \pm 0.21$ & $2.97 \pm 0.54$ & & \\
\hline & Prob. & 0.0001 & 0.0001 & 0.0001 & 0.0001 & & \\
\hline & $\mathrm{LSD}_{0.5}$ & 1.19 & 0.059 & 0.21 & 0.12 & & \\
\hline
\end{tabular}

*Means with the same letters are not significantly different from each otherat $\mathrm{P} \leq 0.05 ; \mathrm{GW}=$ Grain weight, $\mathrm{GL}=\mathrm{Grain}$ length, $\mathrm{GWi}=$ Grain width, GSh $=$ Grain shape. ${ }^{\ngtr} \mathrm{S} \& \mathrm{~B}=$ short $\&$ bold, $\mathrm{L} / \mathrm{SL}=$ Long/slender, $\mathrm{M}=$ medium, $\mathrm{SL}=$ slender. $\S \mathrm{W}=$ white color, $\mathrm{M}=$ mixed color 


\section{Discussion}

Significant variation was observed in agronomic traits evaluated among the 20 rice cultivars including plant height, leaf area, number of panicles per plant, panicle weight, panicle length, number of seeds per panicle and days to $50 \%$ flowering. "Mass I", "Onuogwu" and "E4197" were the tallest among the twenty rice varieties studied. However, these three relatively tall varieties were not as tall as the African and Philippine upland varieties reported by Chang et al.[11] which were observed to be generally more than 150 $\mathrm{cm}$ under upland planting conditions. Chang et al.[11] had pointed out that the lowland rice varieties generally grew much shorter, while the semi-dwarf types seldom exceeded $80 \mathrm{~cm}$. Mass "III" and some other varieties could be neatly classified as dwarf having maintained a dwarf phenotype.

Majority of rice farmers prefer tall plants to lessen the burden of bending down to cut the panicles with a knife during harvesting. Moreover, tall plants have long rice straws needed to mix with clay in building tents among the indigenous people. However, extremely tall cultivars have a tendency to lodge which could be a very serious problem especially under swampy, lowland conditions. This serious lodging effect especially among the tall African rice species (O. glaberrima) makes the high yielding, relatively short $O$. sativa cultivars or their interspecific hybrids (i.e. O. glaberrima x $O$. sativa) preferable. Apart from the significant variation observed for plant height among the cultivars designated as MASS (i.e. MASS1, I, \& III), this pooled group of long grain rice probably arising from a mixture of different cultivars, expectedly displayed significant variation for all the other traits assessed.

The panicle traits are important yield attributes of rice and include number of panicles per plant, panicle weight, panicle length and number of seeds per panicle. These traits affect the overall rice yield as they are often used as a guide to assess the performance of a particular rice cultivar. Based on the data collected by Pramod et al[12] for lowland rice, the range of mean values for different panicle traits were 15.6 $25.5 \mathrm{~cm}$ for panicle length, $7.6-13.2$ for number of panicle per plant, and for panicle weight: $0.9-5.7 \mathrm{~g}$. These values can vary depending on the variety and environmental factors. The panicle weight of "Chinyereugo" and a few others were higher than this range of values reported by Pramod et al.[12], while others fell within the range. Majority of the rice varieties studied had panicle lengths higher than the above reported values. Although the actual varietal name for "Chinyerugo" is not yet known, the word itself "God has given a crown" which symbolizes a rice variety with bumper harvest as observed by the local farmers. This variety "Chinyereugo" accordingly had the highest panicle weight and number of seeds per panicle which indicated the potentially high yielding ability as observed by the farmers. "Mass I" and "Mass II" had the highest values for leaf area. This presupposes that photosynthetic activities will be higher in such varieties, suggesting a better yield. Flowering time indicates the onset of seeding. "Mass I", "Onuogwu",
"Faro15" and "Faro14" took longer times to flower suggesting that they are late flowering, while "Chinyereugo", "Faro15" and "Faro14" flowered within a relatively shorter time suggesting earliness. "Co-operative", "Chinyereugo", "E4334", "E4077", "E4197", "Awilo", and "Onuogwu" all had high number of seeds per panicle which is a desirable trait to farmers.

The increase in some of these agronomic characters could be attributed to some factors stated by Jun et al.[13] that plant height and leaf area affects panicle traits and that plants with good leaf area and increased plant height could utilize sunlight energy for photosynthesis more efficiently. Such rice varieties therefore have the potential for high yield as a result of effective utilization of sunlight which would increase the rate of photosynthesis. The other varieties with somewhat reduced leaf area showed reduced panicle traits which would invariably reduce the potential yield. Despite the observed variations in all these traits, all the varieties had the normal range of values for all the traits studied as reported by Pramod et al.[12], except for traits like number of seeds per panicle and days to $50 \%$ flowering, which are in conformity with the values given by Vange and Obi[14] who studied the effect of planting date on some agronomic traits.

The values of the grain qualities are consistent with the range of values reported by Webb[15], which are also in line with the official range of values for determining the grain configurations. The grain colour for all the newly introduced hybrid rice varieties was white; while a few of the domestic (farmers') cultivars had mixed colours. The grain of one of the newly introduced hybrid varieties, "E4314", was the longest of the varieties studied. This is a quality trait that is well desired by rice consumers. Most of these long-grained varieties seem to be better than the so-called "foreign rice" (e.g. Uncle Ben's rice) in grain length. Therefore, as Nigerian consumers prefer long-grained rice, these suitable types observed in this study may be preferably cultivated in large hectarages to overcome the continual dependence on imported "long-grained" rice that may not be superior to it.

\section{Conclusions}

The new varieties should not replace the existing indigenous ones since majority of the indigenous varieties have got several advantages over some of them especially in most of the agronomic traits. Farmers should therefore, be critical in accepting new varieties that may not be comparably outstanding in a holistic sense.

\section{REFERENCES}

[1] R. P. Cantral and T. G. Reeves, 2002, The cereal of the World's Poor Takes Center Stage, Science 296, 53

[2] M. P. Jones, 1995, The rice plant and its environment, WARDA Training Guide 2, 27 -30 
[3] H. Desrosiev, 1999, Gelatinization Temperature of Cereal Crops, Agricultural Biotechnology, $3^{\text {rd }}$ Edition, Wiley and Sons, New York, 231-234

[4] International Rice Research Institute, 2008, The rice plant and how it grows, Manila, Philippines, 7

[5] National Research Council, 1996, Lost Crops of Africa: Grains, National Academies Press, Washington, DC, 17

[6] E. O. Imolehin and A. E. Wada, 2000, Meeting the rice production and consumption demand in Nigeria with improved technologies, International Rice Commission Newsletter 49, $23-41$

[7] C. M. Perez, B. O. Juliano, C. G. Paschal and V. G. Novenario, 1987, Extracted lipids and carbohydrates during washing and boiling of milled rice, Journal of Starch 39, 386-390

[8] B. N. Singh, S. Fagade, M. M. Ukwungwu, C. William, S. S. Jagtap, O. Oladimeji, A. A. Efisue, and O. Okhidievbie, 1997, Rice growing environments and biophysical constraints in different agro-ecological Zones in Nigeria, Journal of Meteorology $1,35-37$

[9] F. R. Moormann and A. S. R. Juo, 1986, Present land use and cropping system, The Wetland and Rice in Sub-Saharan Africa, I.I.T.A. Ibadan, $191-194$
[10] D. Horna, M. Smale, and M. Vonopper, 2005, Farmers' willingness to pay for seed-related information on rice varieties in Nigeria and Benin. Education Plan Transfer Discussion paper $142,11-12$

[11] T. T. Chang, S. D. Sharma, C. R. Adair and A. T. Perez, 1972, Manual for field Collection of rice, IRRI, Los Banos, Phillipines, 3

[12] T. Pramod, Y. P. Abrol, and K. Suman, 2009, Collection and conservation of rice germplasm in India: Biodiversity and its Significance. I. K. International Group, 128

[13] M. A. Jun, M. A. Wen - bo, M. Dong - Feng, Y. Shing-ming, and Z. Qing - seng, 2007, Characteristics of the rice plant with heavy panicle. Agricultural Science in China 5(12), 911-918

[14] T. Vange, and I. Obi, 2006, Effect of planting date on some agronomic traits of wetland rice varieties at Markurdi, Benue State (Nigeria), Journal of Sustainable Development in Agriculture and Environment 2, $80-84$

[15] B. D. Webb, 1985, Criteria of rice quality in the United States. Rice Chemistry and Technology, $2^{\text {nd }}$ Edition. American Association of Cereal Chemists, 774 - 776 